\title{
CONVENTIONAL LOCOMOTIVE COUPLING TESTS
}

\author{
Patricia Llana \\ Karina Jacobsen \\ David Tyrell \\ Volpe National Transportation Systems Center \\ United States Department of Transportation \\ Cambridge, Massachusetts, USA
}

\begin{abstract}
Research to develop new technologies for increasing the safety of passengers and crew in rail equipment is being directed by the Federal Railroad Administration's (FRA's) Office of Research, Development, and Technology. Crash energy management (CEM) components which can be integrated into the end structure of a locomotive have been developed: a pushback coupler and a deformable anti-climber. These components are designed to inhibit override in the event of a collision. The results of vehicle-to-vehicle override, where the strong underframe of one vehicle, typically a locomotive, impacts the weaker superstructure of the other vehicle, can be devastating. These components are designed to improve crashworthiness for equipped locomotives in a wide range of potential collisions, including collisions with conventional locomotives, conventional cab cars, and freight equipment.

Concerns have been raised in discussions with industry that push-back couplers may trigger prematurely, and may require replacement due to unintentional activation as a result of service loads. Push-back couplers are designed with trigger loads meant to exceed the expected maximum service loads experienced by conventional couplers. Analytical models are typically used to determine these required trigger loads. Two sets of coupling tests are planned to demonstrate this, one with a conventional locomotive equipped with conventional draft gear and coupler, and another with a conventional locomotive equipped with a push-back coupler. These tests will allow a performance comparison of a conventional locomotive with a CEM-equipped locomotive during coupling. In addition to the two sets of coupling tests, car-to-car compatibility tests of CEM-equipped locomotives, as well as a train-to-train test are also planned. This arrangement of tests allows for evaluation of the CEM-equipped
\end{abstract}

locomotive performance, as well as comparison of measured with simulated locomotive performance in the car-to-car and train-to-train tests.

This paper describes the results of the coupling tests of conventional equipment. In this set of tests, a moving locomotive was coupled to a standing cab car. The coupling speed for the first test was $2 \mathrm{mph}$, the second test $4 \mathrm{mph}$, and the tests continued with the speed incrementing by $2 \mathrm{mph}$ until the last test was conducted at $12 \mathrm{mph}$. The damage observed resulting from the coupling tests is described. The lowest coupling speed at which damage occurred was $6 \mathrm{mph}$. Prior to the tests, a onedimensional lumped-mass model was developed for predicting the longitudinal forces acting on the equipment and couplers. The model predicted that damage would occur for coupling speeds between 6 and $8 \mathrm{mph}$. The results of these conventional coupling tests compare favorably with pre-test predictions. Next steps in the research program, including future full-scale dynamic tests, are discussed.

\section{BACKGROUND}

The Office of Research, Development, and Technology of the Federal Railroad Administration (FRA) and the Volpe Center are continuing to evaluate new technologies for increasing the safety of passengers and operators in rail equipment. In recognition of the importance of override prevention in train-totrain collisions in which one of the vehicles is a locomotive [1, $2,3]$, and in light of the proven benefits of crash energy management (CEM) technologies in passenger trains [4], FRA seeks to evaluate the effectiveness of CEM components on locomotive equipment. Research is being conducted to design and integrate CEM into the end structure of a conventional 
locomotive to mitigate the effects of a collision and, in particular, to prevent override in head-on collisions [5].

A research program has been recently conducted that developed, fabricated and tested two CEM components for the forward end of a locomotive. These components are: (1) a deformable anti-climber (DAC), and (2) a push-back coupler (PBC) [6, 7]. Detailed designs for these components were developed, and the performance of each design was evaluated through large deformation dynamic finite element analysis (FEA). Two test articles were fabricated and individually dynamically tested against a test wall in order to verify certain performance characteristics of the two components relative to specific requirements. The tests were successful in demonstrating the effectiveness of the two design concepts. Test results were consistent with finite element model predictions in terms of energy absorption capability, force-displacement behavior, and modes of deformation.

This research program will eventually integrate the two CEM components onto a locomotive in order to demonstrate that these components work together to mitigate the effects of a collision and prevent override [8]. A series of dynamic CEM coupling tests is planned to demonstrate that the push-back coupler will, or will not, trigger, depending on the proper conditions. However, before demonstrating the robustness of the push-back coupler, it is important to establish a baseline for conventional coupling to determine the maximum nondestructive conventional coupling speed. Therefore, conventional coupling tests were conducted. The coupling tests were conducted repeatedly with the same F40 locomotive and M1 passenger car, starting at $2 \mathrm{mph}$ for the first test, and increasing in increments of $2 \mathrm{mph}$. The test requirements and pre-test analysis are detailed in a companion paper [9]. This paper describes the test setup, equipment, test implementation and test results. The results of the tests are then compared to the pre-test analysis. The paper concludes with a summary evaluation and the next steps in the research program.

\section{TEST SCENARIO: COUPLING IMPACT}

The conventional coupling tests were conducted at the Transportation Technology Center (TTC) in Pueblo, Colorado on November 18-19, 2015.

\section{Test Setup}

The coupling tests were conducted repeatedly with the same conventional F40 locomotive and M1 cab car, starting at $2 \mathrm{mph}$ for the first test, and increasing in increments of $2 \mathrm{mph}$, as shown schematically in Figure 1. At impact, the F40 locomotive was traveling at speed and the M1 cab car was braked. The couplers on both vehicles were open upon impact and expected to couple with each other. A total of six impact tests were conducted, with the final test conducted at a target speed of $12 \mathrm{mph}$. The vehicle weights were approximately 246 kips for the locomotive, and 73 kips for the M1 car.

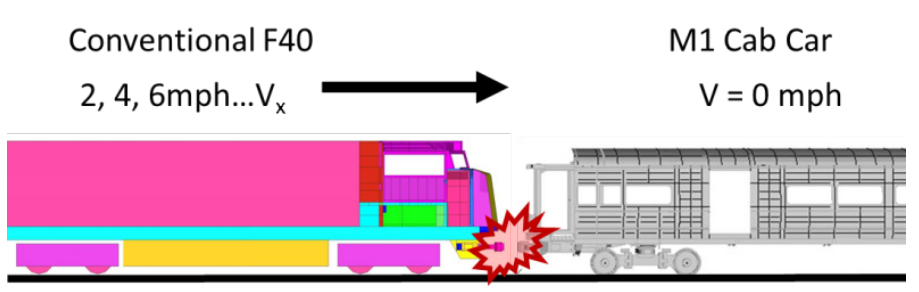

Figure 1. Schematic of coupling test initial conditions

The objective of this effort was to determine the maximum non-destructive conventional coupling speed by conducting conventional coupling tests. This will establish a baseline for comparison with future CEM coupling tests. The structural performance of the conventional coupler and the coupling vehicles were measured and characterized under a range of dynamic coupling speeds.

The information measured from the conventional coupling tests includes the longitudinal, vertical and lateral accelerations of the equipment and the displacements of the couplers. The equipment and components were visually inspected externally after each coupling test to ascertain the condition of the equipment and determine if any damage had occurred. However, due to the nature of couplers, draft gears, and draft pockets, there was difficulty in inspecting the internal areas, such as the draft gear pocket and draft gear components, for damage. Additionally, conducting a complete a teardown of the draft gear systems of both the locomotive and cab car after each impact test was not practical. A borescope was employed on the M1 car after the $8 \mathrm{mph}$ test to try to determine if there was damage to the draft gears and inside the draft gear pockets. However, the quality of the borescope images proved unhelpful in this endeavor. A higher-quality borescope equipped with a light will be employed for the next series of tests in order to inspect internal areas of the draft gear systems of both vehicles. A post-test inspection of the equipment, including a complete teardown of the draft gear systems of both vehicles, was conducted and is described in the results section of the paper.

The force-displacement characteristic (i.e., the load that the couplers and supporting structure develop during the coupling procedure) is a key characteristic of the couplers and the cars. One purpose of these tests was to take measurements for comparison with analytical predictions in order to validate that such predictions are accurate. A second comparison will be with the measurements taken for the upcoming PBC coupling tests.

\section{Equipment}

The equipment used in the conventional coupling tests were conventional F40 locomotive No. 202 and M1 passenger cab car No. 9324, shown in the pre-test photograph of Figure 2. As can be seen in the photograph, this M1 cab car exhibits damage from a small fire. However, the structural elements of the end frame were unharmed and intact and the rest of the vehicle was undamaged. 


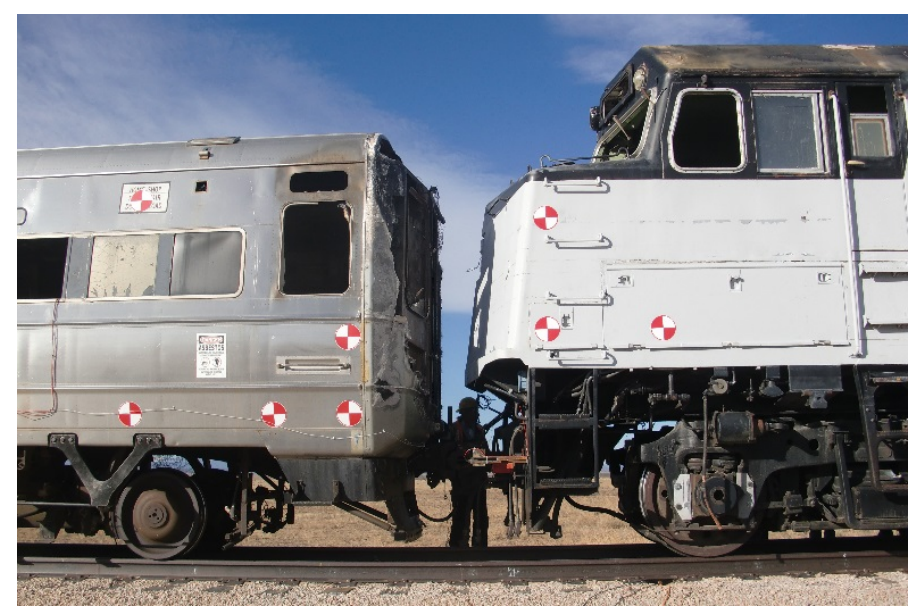

Figure 2. Pre-test photos of M1 cab car No. 9324 (left) and F40 locomotive No. 202 (right) used in the conventional coupling tests

\section{Instrumentation}

Measurements were made with accelerometers, displacement transducers, and high speed video cameras. This instrumentation was intended to capture the gross motions of the equipment, the relative motion of the couplers and draft gear, and the sequence of events, e.g., coupling, stroking of the draft gears, and eventual damage. The coupling speed of the locomotive was measured with radar and a reflector-based sensor.

Figure 3 shows a schematic illustration of the accelerometer locations for the M1 car. Accelerometers were placed in similar locations on the F40 locomotive. The accelerometers on the carbody captured the three dimensional gross motions of the carbody - longitudinal, lateral, and vertical accelerations, as well as yaw, pitch, and roll. Seventeen accelerometer channels and eight displacement transducer channels were utilized for each vehicle, resulting in fifty total data channels.

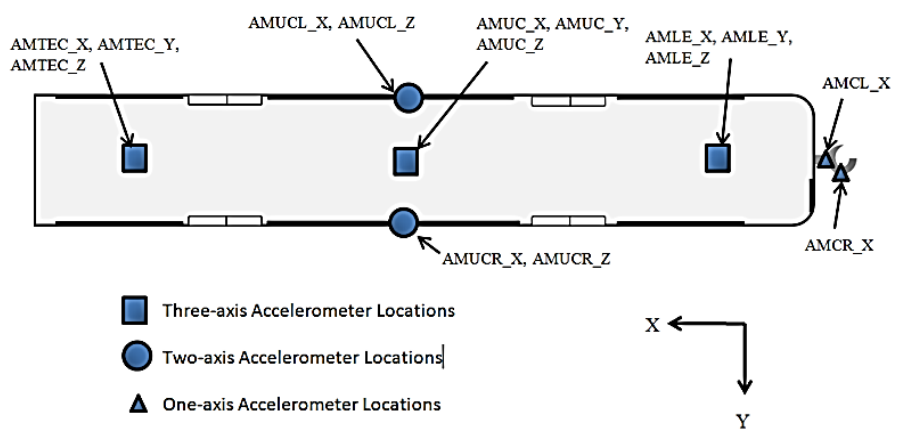

Figure 3. Schematic illustration of M1 cab car accelerometer locations

Six high frame rate and four conventional frame rate high definition (HD) video cameras documented each impact. The tests were conducted on tangent track with approximately a $0.85 \%$ grade. The locomotive was rolled back from the M1 cab car and released from the appropriate location to develop the intended impact speed. Speed trials were conducted prior to the test date to determine the distance needed to roll back the locomotive for each desired impact speed. Shortly before each test the release distance was adjusted based on wind speed and direction.

\section{TEST RESULTS}

Table 1 shows the actual speeds achieved for each impact test. All actual speeds were within $+/-0.3 \mathrm{mph}$ of the corresponding target speed. In all but the last two tests $(10 \mathrm{mph}$ and $12 \mathrm{mph}$ ), the vehicles coupled together at impact. The vehicles remained on the tracks for all of the coupling tests. After each coupling test, a visual inspection of both vehicles was conducted by several Volpe and TTCI personnel to look for structural damage resulting from the impact.

\section{Table 1. Target Speeds vs Test Speeds}

\begin{tabular}{|c|c|c|}
\hline Test & $\begin{array}{c}\text { Target Speed } \\
(\mathbf{m} \mathbf{p h})\end{array}$ & $\begin{array}{c}\text { Actual Speed } \\
(\mathbf{m p h})\end{array}$ \\
\hline $\mathbf{1}$ & 2 & 1.9 \\
\hline $\mathbf{2}$ & 4 & 3.9 \\
\hline $\mathbf{3}$ & 6 & 5.7 \\
\hline $\mathbf{4}$ & 8 & 7.9 \\
\hline $\mathbf{5}$ & 10 & 10.0 \\
\hline 6 & 12 & 11.9 \\
\hline
\end{tabular}

\section{Tests 1 \& 2: $2 \mathrm{mph} \& 4 \mathrm{mph}$}

The actual speeds of the impact tests were $1.9 \mathrm{mph}$ and 3.9 mph. The vehicles coupled upon impact in both tests. Upon visual inspection, there was no apparent structural damage to either the F40 locomotive or the M1 cab car as a result of either impact.

\section{Test 3: $6 \mathrm{mph}$}

The actual speed of the impact test was $5.7 \mathrm{mph}$. The vehicles coupled upon impact. Upon visual inspection, there was no apparent structural damage to the F40 locomotive. Similarly, there was no apparent structural damage to the coupler, draft gear or draft pocket of the M1 cab car. However, there was some very minor dimpling of the M1 car shell at the front left side sill connection to the truck, as indicated by the red circles of Figure 4.

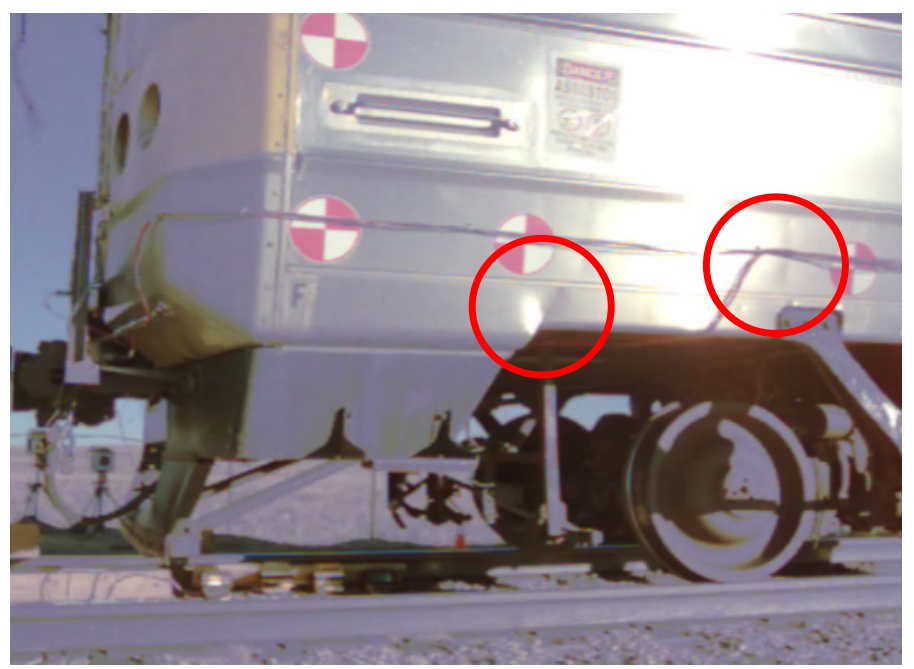

Figure 4. Dimpling of M1 shell at front left side sill truck connection after $5.7 \mathrm{mph}$ impact test

This material is declared a work of the U.S. Government and is not subject to copyright protection in the United States.

Approved for public release; distribution is unlimited. 


\section{Test 4: $8 \mathrm{mph}$}

The actual speed of the impact test was $7.9 \mathrm{mph}$. The vehicles coupled upon impact. After this impact test, a borescope was employed on the M1 car to try to determine if there was damage to the draft gears and inside the draft gear pockets. However, the quality of the borescope images proved unhelpful in this endeavor. As stated previously, a higher-quality borescope will be employed for the next series of tests in order to inspect internal areas of the draft gear systems of both vehicles.

Upon visual inspection, there was no apparent structural damage to the F40 locomotive. Similarly, there was no apparent structural damage to the coupler, draft gear or draft pocket of the M1 cab car. The dimpling of the M1 car shell at the front left side sill connection to the truck became more pronounced, as indicated by the red circles of Figure 5 .

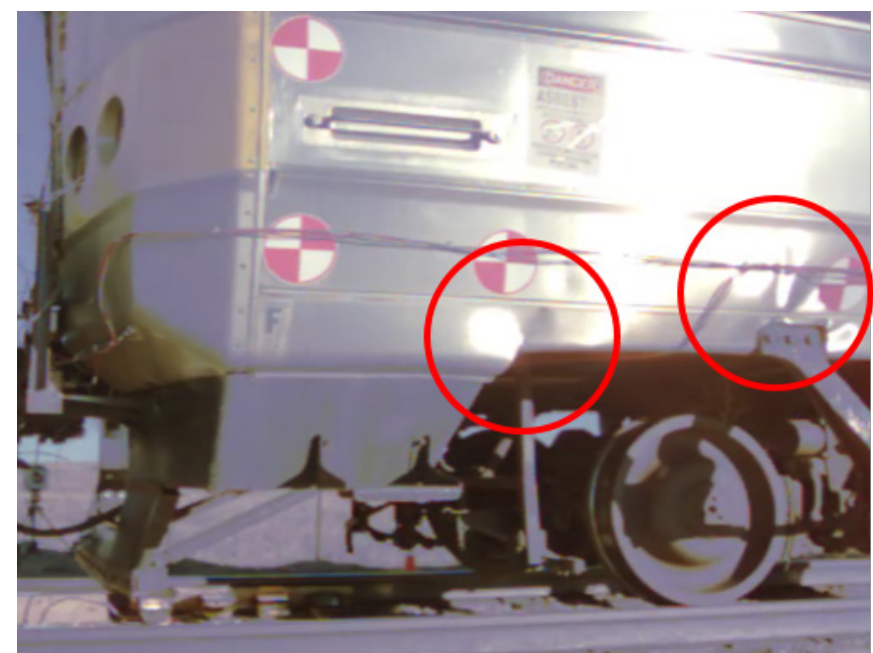

Figure 5. More pronounced dimpling of M1 shell at front left side sill truck connection after $7.9 \mathrm{mph}$ impact test

\section{Test 5: $10 \mathrm{mph}$}

The actual speed of the impact test was $10.0 \mathrm{mph}$. During this test, both the locomotive coupler locking pin and the M1 coupler hinge pin came up due to vertical oscillations of both couplers as a result of the impact. This prevented the vehicles from coupling. The M1 coupler hinge pin can be seen in Figure 6.

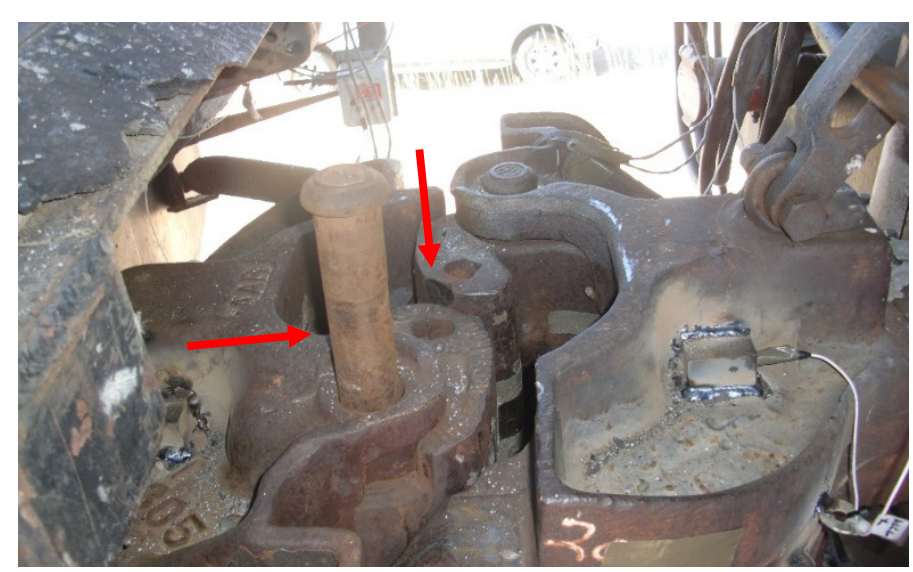

Figure 6. M1 coupler (left) hinge pin and locomotive coupler (right) knuckle damage
Upon visual inspection, there was only very minor damage to the F40 locomotive. A small chip was taken out of the locomotive coupler knuckle, as indicated in Figure 6.

In the M1 car, there was a bulge in the left draft sill at the bellmouth due to the coupler shank pushing on the coupler stops inside the bellmouth. This bulge can be seen inside the red circle in Figure 7. The coupler stops pushed in and deformed by the coupler shank can be seen in Figure 8. The left coupler stop (located on the right side in the photo) has been pushed in more and is more deformed than the right coupler stop.

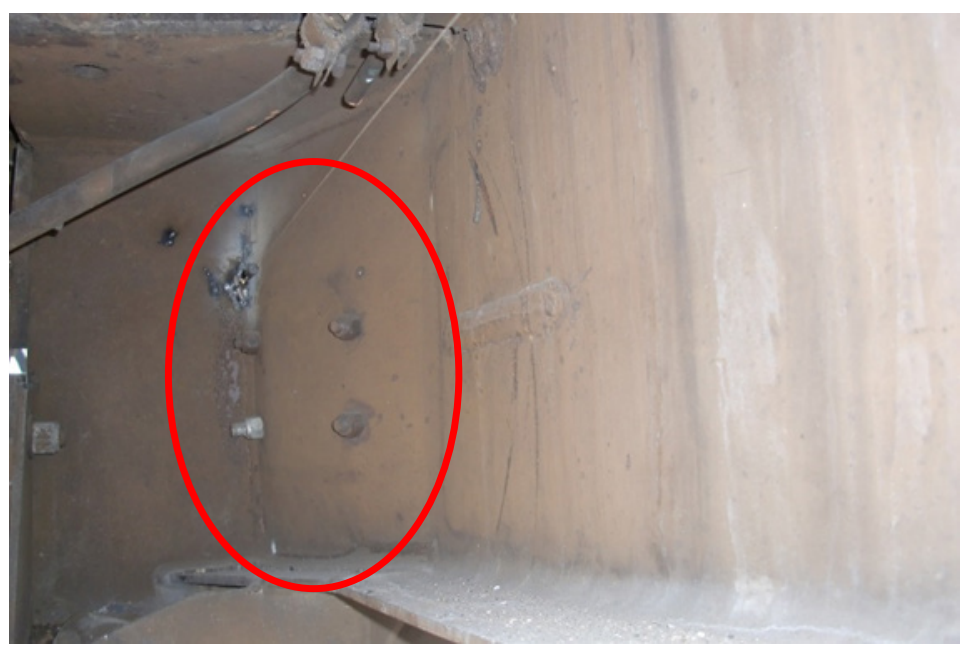

Figure 7. Bulging of M1 left draft sill due to coupler shank pushing on coupler stops inside bellmouth

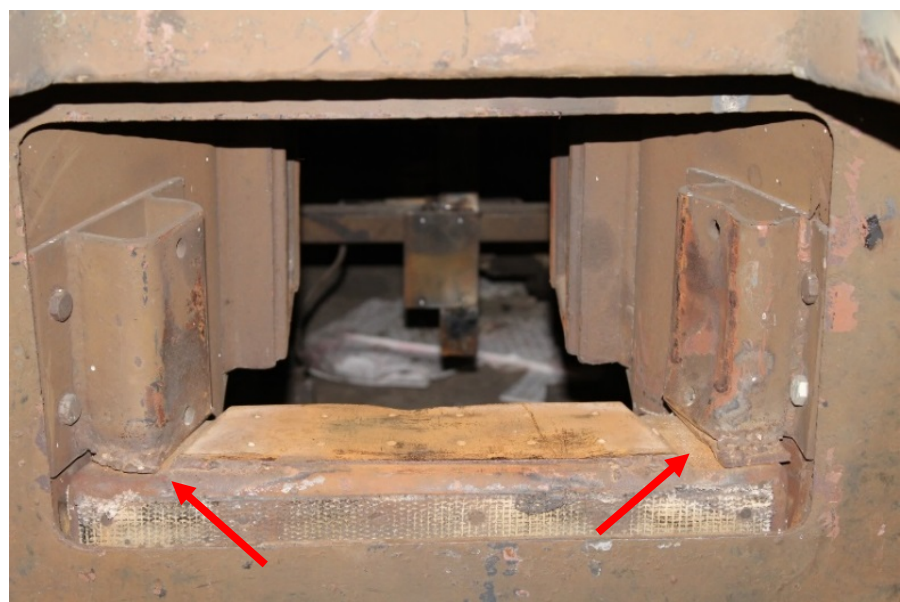

Figure 8. M1 coupler stops deformed by coupler shank

In the $\mathrm{M} 1 \mathrm{car}$, the impact force developed in the $10 \mathrm{mph}$ impact caused the exterior right flange of the draft pocket to deform, as indicated in Figure 9. The force of the impact through the draft gear also caused one of the buff plates in the draft gear to bend, as indicated in Figure 10.

This material is declared a work of the U.S. Government and is not subject to copyright protection in the United States. Approved for public release; distribution is unlimited. 


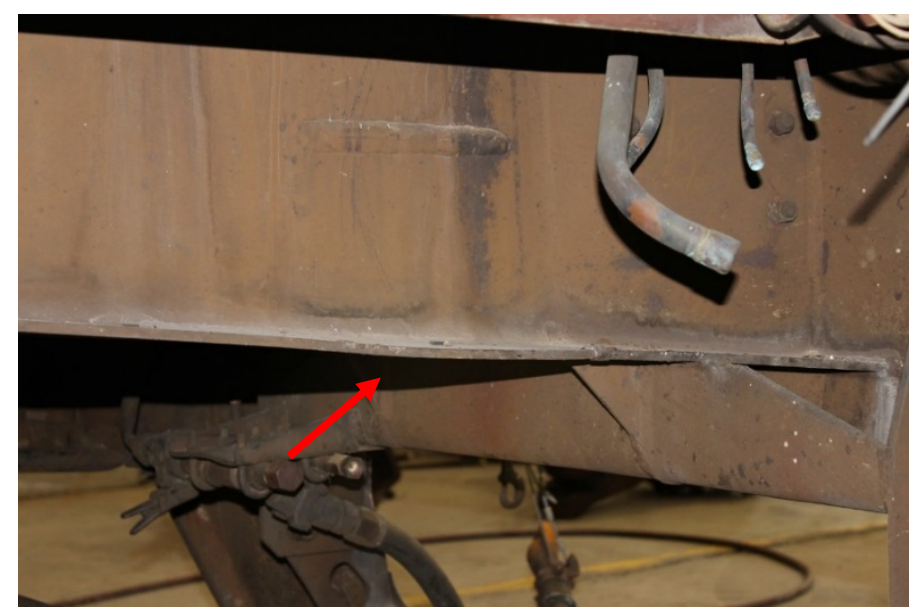

Figure 9. Deformed exterior right flange of M1 draft pocket

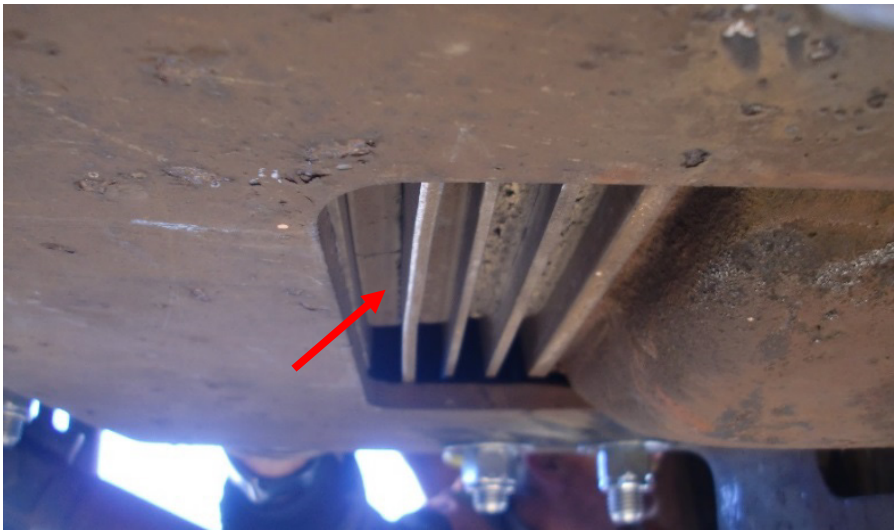

Figure 10. M1 bent buff plate in draft gear

In the M1 car, this impact caused the side sill to buckle at the front left truck connection. Figure 11 shows an exterior view of the buckle of the side sill, and Figure 12 shows in interior view of the buckled side sill at the front left truck connection. There was also some minor dimpling of the M1 shell at the side sill on the right side at the front truck connection, but the damage was more extensive on the left side.

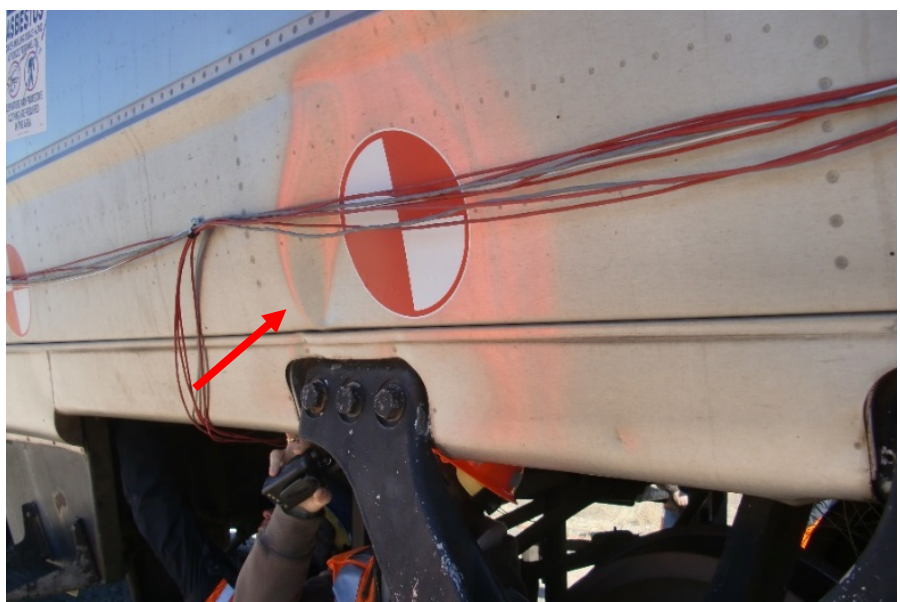

Figure 11. M1 side sill buckled at front left truck connection (exterior view)

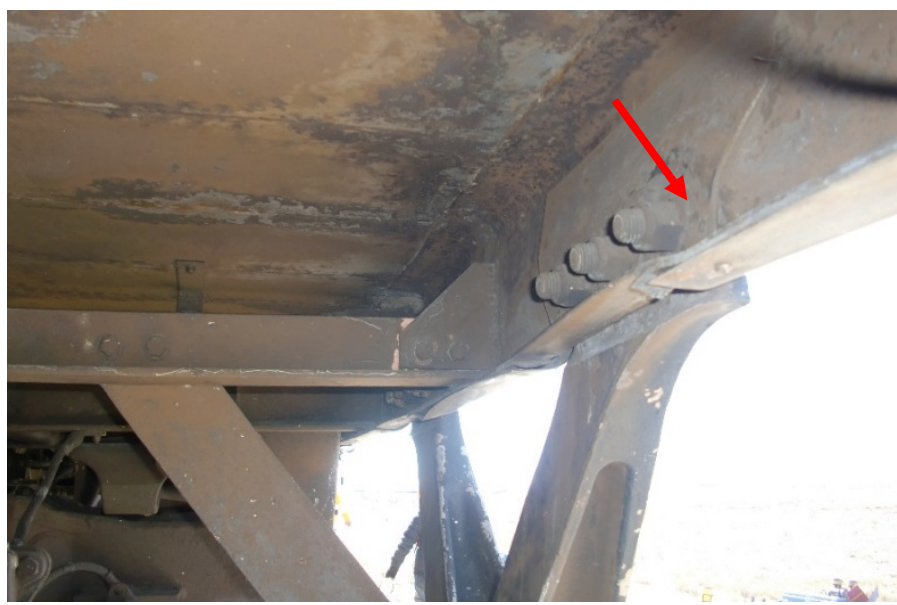

Figure 12. M1 side sill buckled at front left truck connection (interior view)

\section{Test 6: $12 \mathrm{mph}$}

The actual speed of the impact test was $11.9 \mathrm{mph}$. As in the $10 \mathrm{mph}$ test, the vehicles did not couple during this test, and the M1 coupler hinge pin again lifted during impact. Upon visual inspection, there was no apparent additional damage to the F40 locomotive.

In the M1 car, the $12 \mathrm{mph}$ impact caused damage at the side sill front left truck connection, as shown in Figure 13. The impact also caused an underframe member to deform near the front left truck, as shown in Figure 14, and the front belt loop of the front truck to be severed, as shown in Figure 15.

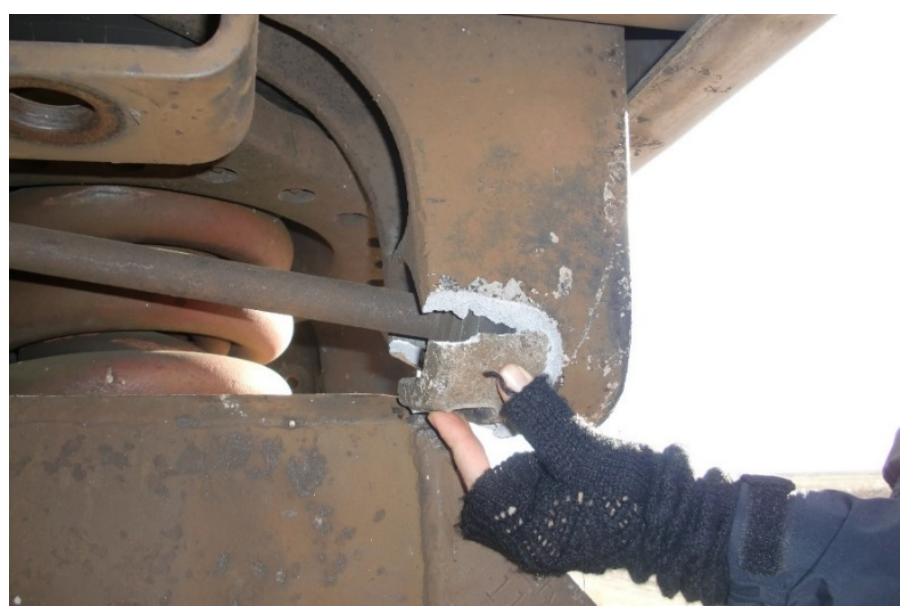

Figure 13. M1 side sill front left truck connection damage

This material is declared a work of the U.S. Government and is not subject to copyright protection in the United States. Approved for public release; distribution is unlimited. 


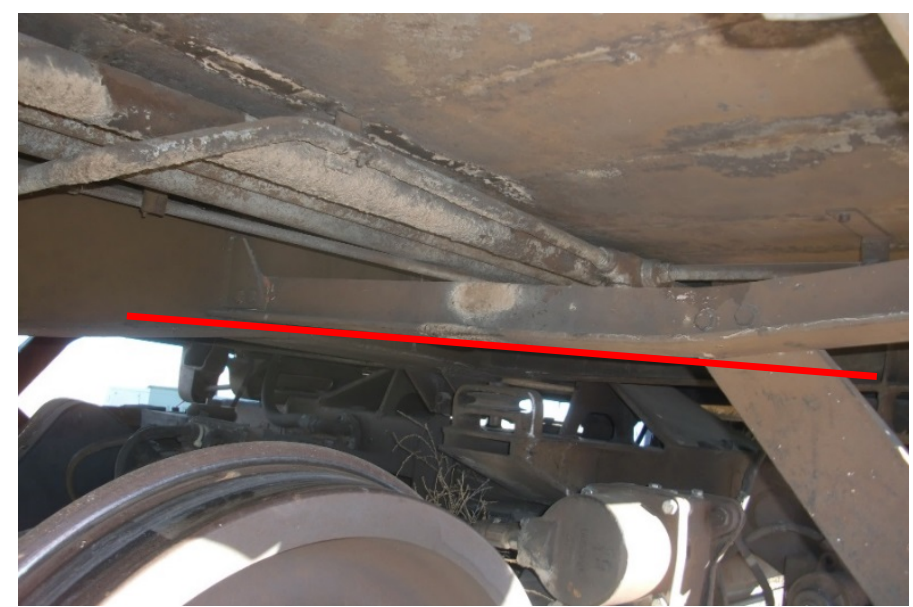

Figure 14. M1 underframe member bent near front truck connection, left side

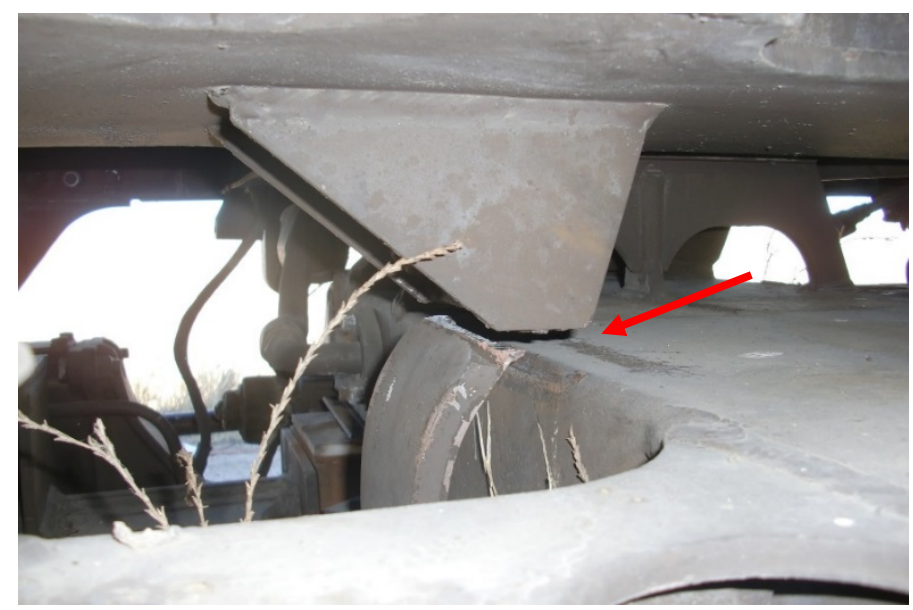

Figure 15. M1 front belt loop of front truck severed

The 12 mph impact worsened the buckle at the side sill front left truck connection, as shown in the exterior view of Figure 16 and the interior view of Figure 17, effectively crippling the M1 car. The red arrows in Figure 17 indicate cracks in the side sill. The minor dimpling that occurred in the $10 \mathrm{mph}$ impact on the front right shell at the side sill connection to the front right truck worsened to buckling of the side sill at this location due to the 12 mph impact. This can be seen in the exterior view of Figure 18 and the interior view of Figure 19. The red arrows in Figure 19 indicate cracks in the side sill.

Testing was halted after this test as there was extensive damage to the M1 cab car.

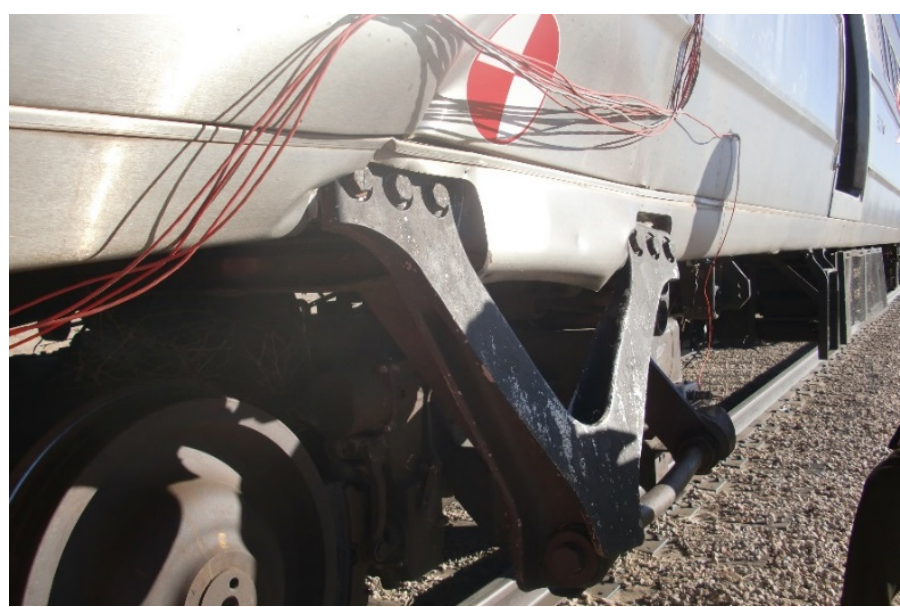

Figure 16. M1 side sill front left truck connection (exterior view)

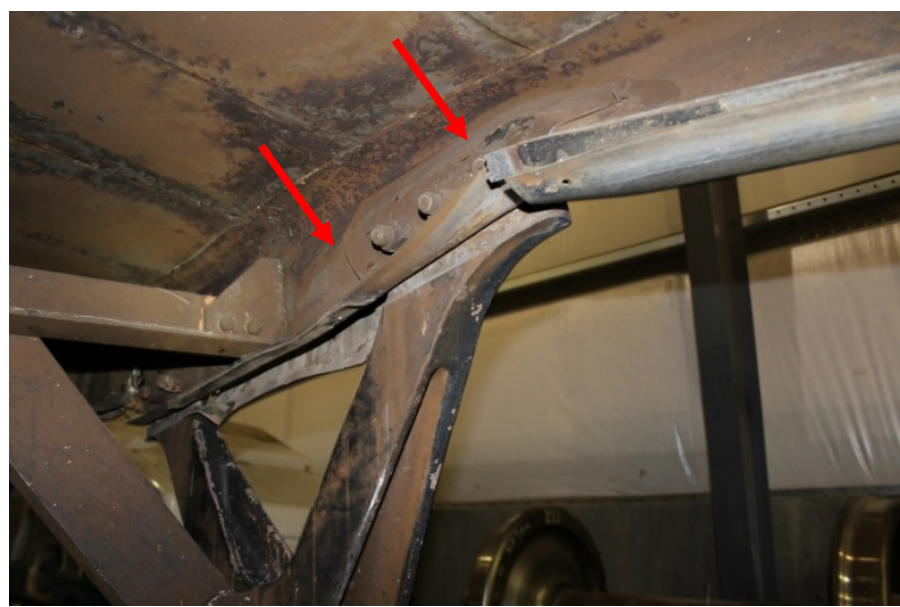

Figure 17. M1 side sill front left truck connection (interior view)

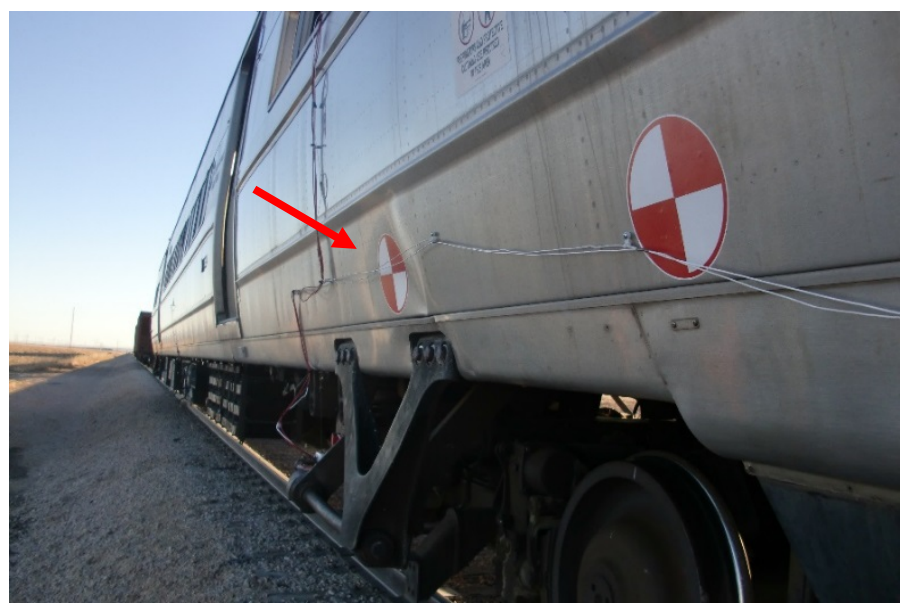

Figure 18. M1 side sill front right truck connection (exterior view)

This material is declared a work of the U.S. Government and is not subject to copyright protection in the United States. Approved for public release; distribution is unlimited. 


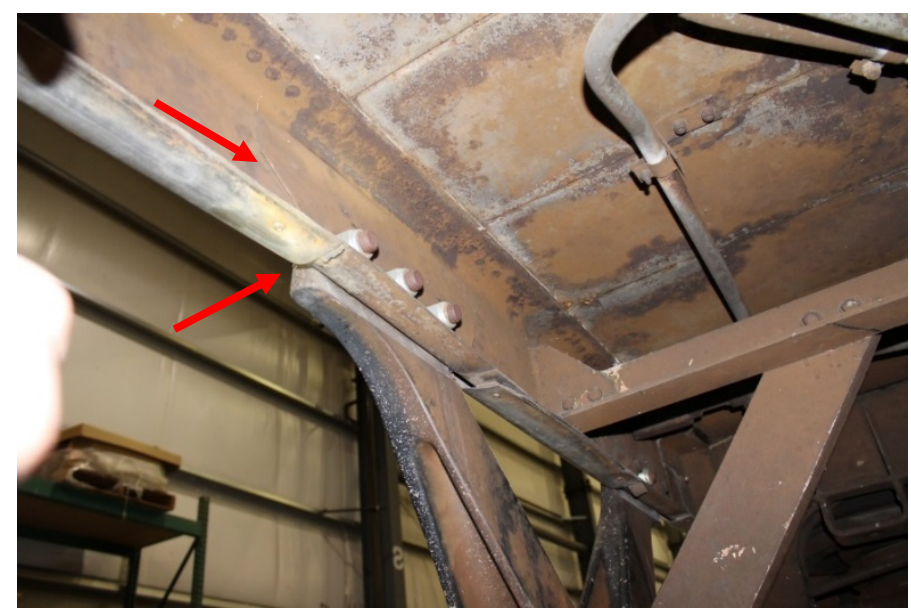

Figure 19. M1 side sill front right truck connection (interior view)

\section{Damage to Draft Systems}

After the tests were conducted, a post-test teardown of the vehicle draft gear systems was performed to determine the internal damage sustained as a result of the six impact tests. A thorough inspection of the F40 locomotive draft gear and draft pocket showed no apparent structural damage to the draft gear system and draft pocket.

The post-test inspection of the M1 cab car draft gear and draft pocket revealed that the longitudinal members on both sides of the draft pocket were deformed, as shown in Figure 20 and Figure 21. Two of the buff plates of the M1 draft gear were also bent as a result of the six impact tests, as shown in Figure 22.

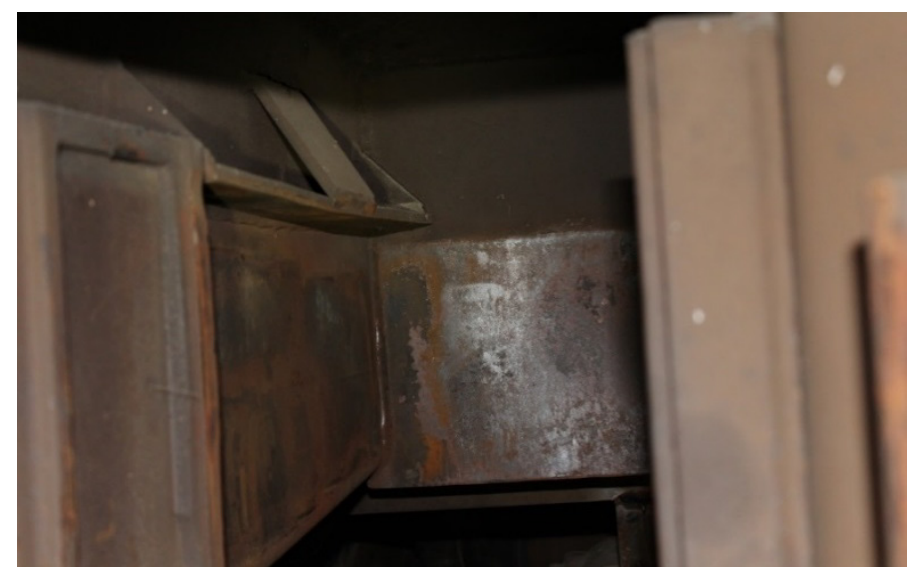

Figure 20. M1 interior draft pocket bent longitudinal member, right side

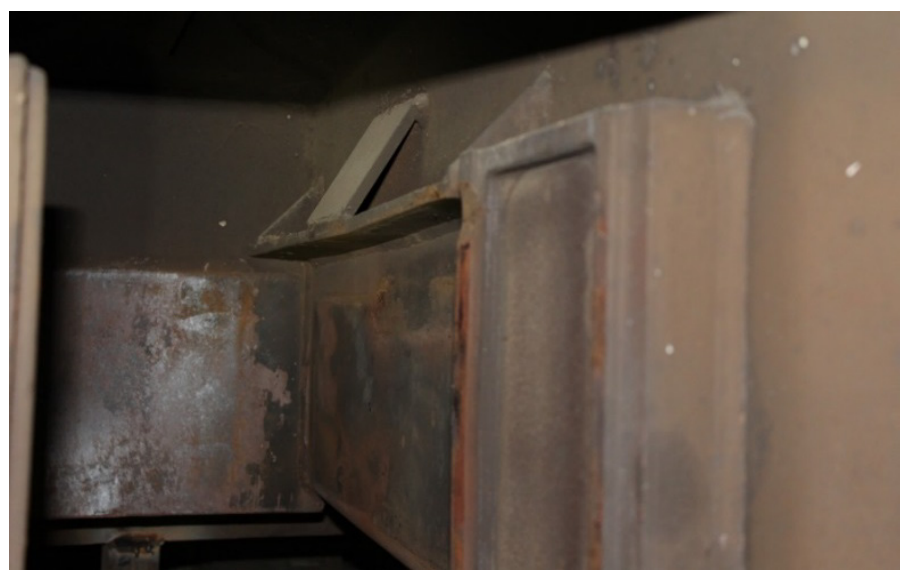

Figure 21. M1 interior draft pocket bent longitudinal member, left side

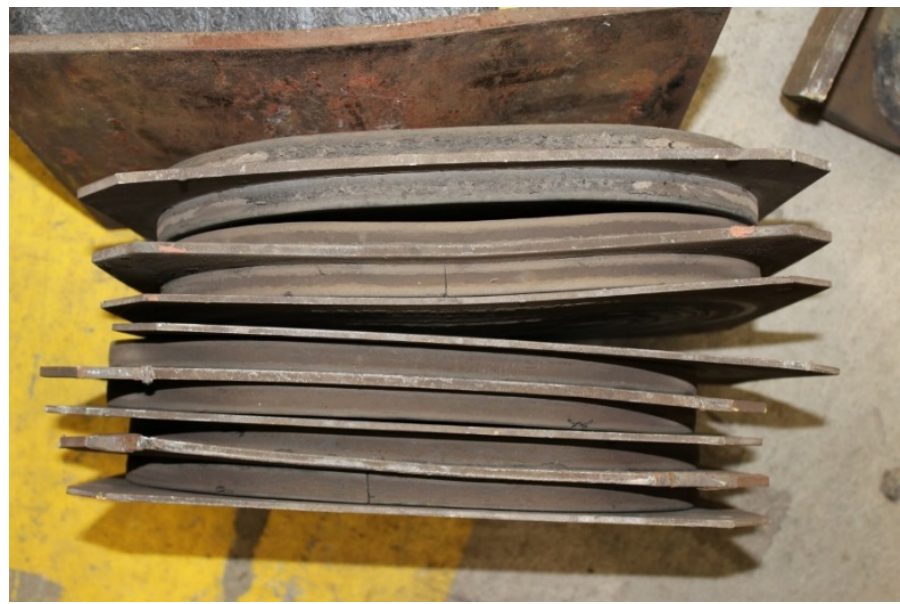

Figure 22. M1 bent buff plates

\section{Test Data}

The test data were filtered using a channel frequency class (CFC) 60 filter consistent with the requirements of SAE J211. Forces were obtained from the accelerometer data by multiplying the mass of the vehicle by the acceleration measured at each accelerometer location. The initial impact energy was calculated using the actual impact speed and the mass of the locomotive. The impact forces and impact energies associated with each test are summarized in Table 2. The locomotive carbody accelerometer data was used in these calculations.

\section{Table 2. Impact Forces \& Energies}

\begin{tabular}{|c|c|c|c|}
\hline Test & $\begin{array}{c}\text { Impact } \\
\text { Speed } \\
\text { (mph) }\end{array}$ & $\begin{array}{c}\text { Impact Force } \\
\text { (kips) }\end{array}$ & $\begin{array}{c}\text { Impact Energy } \\
\text { (ft-kips) }\end{array}$ \\
\hline $\mathbf{1}$ & 1.9 & 137 & 29 \\
\hline $\mathbf{2}$ & 3.9 & 258 & 123 \\
\hline $\mathbf{3}$ & 5.7 & 508 & 265 \\
\hline $\mathbf{4}$ & 7.9 & 963 & 513 \\
\hline $\mathbf{5}$ & 10.0 & 1321 & 817 \\
\hline $\mathbf{6}$ & 11.9 & 1732 & 1160 \\
\hline
\end{tabular}

The coupling force as a function of the impact speed is plotted in Figure 23. The plot is annotated to show the

This material is declared a work of the U.S. Government and is not subject to copyright protection in the United States. Approved for public release; distribution is unlimited. 
progression of damage to the M1 cab car. Again, very little damage was incurred by the locomotive through all six impact tests. As shown in the figure, no damage to the M1 occurred in the first two impact tests $(1.9 \mathrm{mph}$ and $3.9 \mathrm{mph})$. Dimpling of the M1 shell at the location where the side sill meets the front truck attachment occurred as a result of the $5.7 \mathrm{mph}$ impact. This dimpling became more pronounced as a result of the $7.9 \mathrm{mph}$ impact. The $10.0 \mathrm{mph}$ impact resulted in more damage to the side sill at the front truck connection, as well as damage to the bellmouth and underframe. The $11.9 \mathrm{mph}$ impact resulted in effectively crippling the side sill of the M1 cab car.

The main objective of this effort was to determine the maximum non-destructive conventional coupling speed. Figure 23 shows the measured coupling force as a function of impact speed. At $2 \mathrm{mph}$ and $4 \mathrm{mph}$, no visible damage occurred to either vehicle. Between $4 \mathrm{mph}$ and $6 \mathrm{mph}$, damage begins to occur. At speeds greater than $6 \mathrm{mph}$, there was visible damage. Therefore, coupling speeds should be kept under $6 \mathrm{mph}$ to prevent damage. This is consistent with the Association of American Railroads' General Code of Operating Rules [11], which specifies that couplings occur "at a speed of not more than $4 \mathrm{mph}$ ".

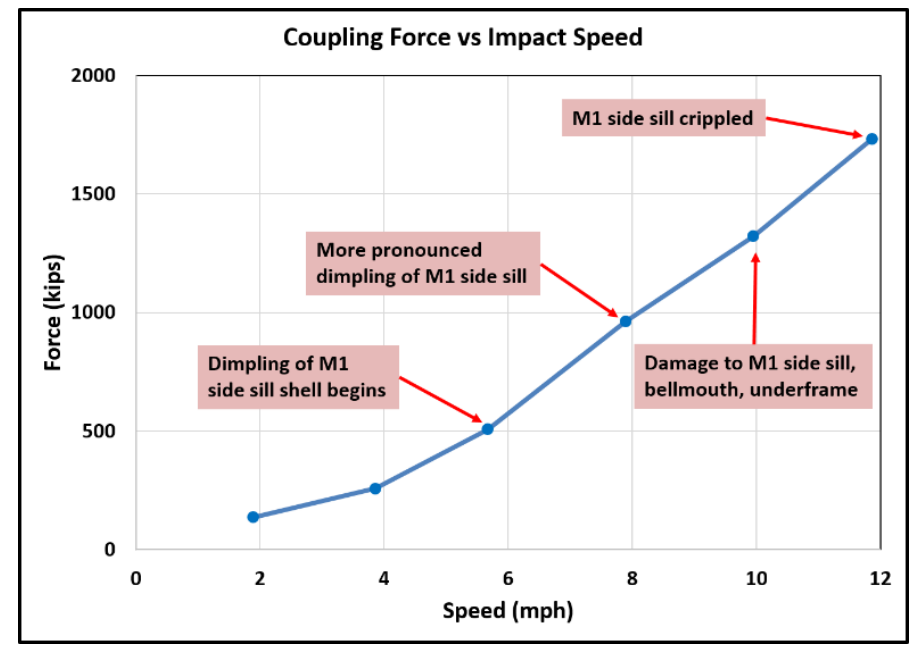

Figure 23. Coupling force as a function of impact speed

\section{COMPARISON TO PRE-TEST ANALYSIS}

A simplified, one-dimensional, two-degree of freedom, dynamic lumped-parameter model of the coupling test was developed prior to the tests, shown schematically in Figure 24. The M1 cab car is represented by a single mass, and the F40 locomotive is also represented by a single mass. The draft gears act as a spring between the two masses. The model includes the longitudinal braking force acting on the M1. The primary purpose of the model was to estimate the peak force acting between the vehicles as a function of coupling speed.

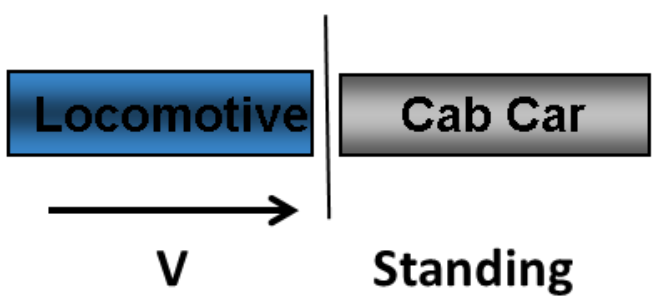

Figure 24. Schematic of one-dimensional two-degree-offreedom lumped parameter coupling model.

Figure 25 shows the force-displacement characteristics input into the simplified model. The characteristic is that of a relatively soft spring with a relatively hard stop. In such cases, the peak force is sensitive to the stiffness of the stop. Accordingly, a range of bottoming stiffnesses were analyzed: stiff, nominal, and soft. The bottoming stiffness is a function of both the draft gear itself and the support provided to the draft gear by the locomotive and cab car underframes.

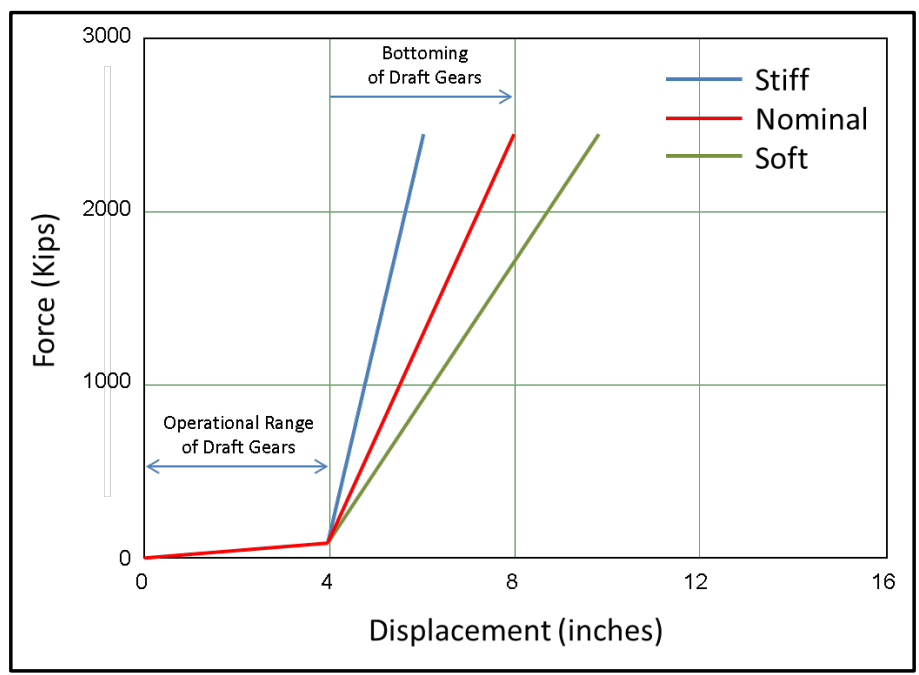

Figure 25. Input force-displacement characteristics for lumped-parameter model.

Figure 26 shows peak coupling force as a function of coupling speed, for the three bottoming stiffnesses: stiff, nominal, and soft. The graph is also annotated with the M1 car elastic strength, static crippling strength, and dynamic crippling strength [10]. Prior to the test, the coupler load was predicted to exceed the M1 cab carbody static elastic strength for coupling speeds between 4 and $7 \mathrm{mph}$. The coupler load was predicted to exceed the M1 cab carbody static crippling strength for coupling speeds between 6 and $10 \mathrm{mph}$. It was predicted that damage would occur for coupling speeds between 6 and $8 \mathrm{mph}$. This compares favorably with the test result that coupling speeds should be kept under $6 \mathrm{mph}$ to prevent equipment damage.

This material is declared a work of the U.S. Government and is not subject to copyright protection in the United States. Approved for public release; distribution is unlimited. 


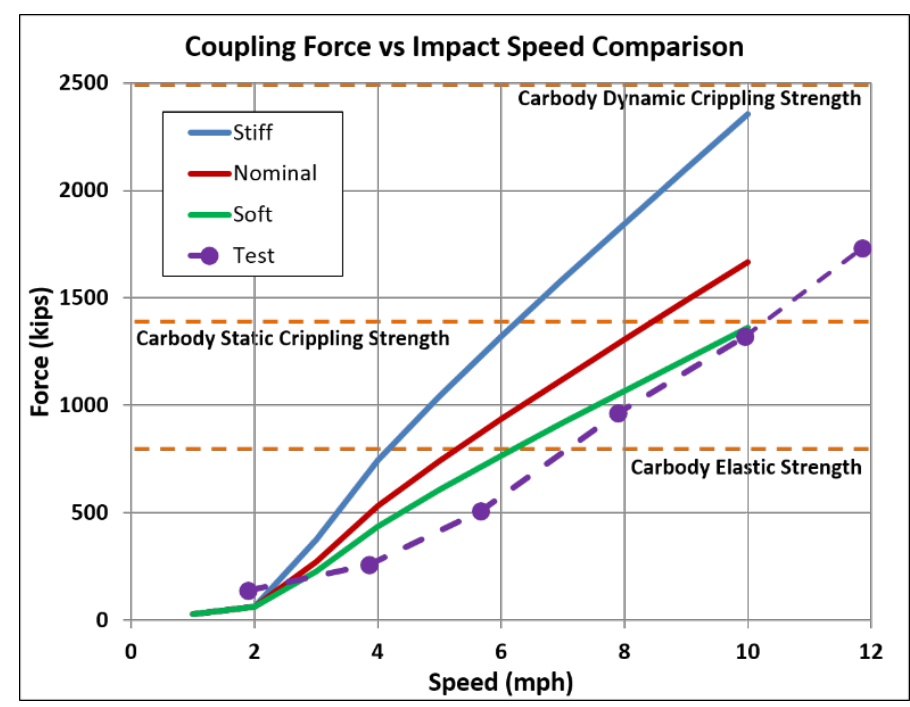

Figure 26. Peak coupling force as a function of coupling speed compared to results from lumped-parameter model

It is important to note that the three M1 carbody strengths and the three predictions shown in Figure 26 are based on the assumption that the load path goes through the carbody alone. However, the dimpling and subsequent crippling of the M1 side sills that resulted from the impact tests indicate that the load path was through the truck attachments. This behavior could not have been captured by the simplified, one-dimensional model, since the entire M1 cab car was represented by a single mass.

The forces measured in the impact tests are also plotted with the model predictions and M1 carbody strengths in Figure 26. Despite the difference in load path, the figure shows that the results of these conventional coupling tests compares favorably with pre-test predictions of the simplified model utilizing the soft stiffness.

\section{SUMMARY}

The FRA, with support from the Volpe Center, is conducting research on the implementation of CEM features on locomotives. These features include pushback couplers and deformable anticlimbers. A series of tests are planned, including coupling tests, car-to-car impact tests, and a train-to-train collision test. This arrangement of tests allows for comparison of conventional with CEM-equipped locomotive measured performance during coupling. Additionally, this arrangement of tests allows for evaluation of the CEM-equipped locomotive performance, as well as comparison of measured with simulated locomotive performance in the car-to-car and train-to-train tests.

In the coupling tests of conventional equipment, the maximum coupling speed for which there is no damage to either vehicle was determined. A moving F40 locomotive was repeatedly coupled to a standing M1 cab car. The coupling speed for the first impact test was $2 \mathrm{mph}$, the second test $4 \mathrm{mph}$, with the tests continuing at incrementing speeds of $2 \mathrm{mph}$ until the last test was conducted at $12 \mathrm{mph}$. Coupling tests of both conventional and pushback couplers will be conducted to compare the performance of each. Coupling speeds which lead to equipment damage were tested for conventional couplers.
Coupling speeds which cause the coupler to trigger are to be tested for pushback couplers.

This paper described the test results and comparison with analysis predictions for the full-scale coupling tests of conventional equipment. The damage resulting from the conventional coupling tests was described. Very minor damage was incurred by the F40 locomotive as a result of all six coupling impacts. The damage was a small chip removed from the locomotive coupler knuckle as a result of the $10 \mathrm{mph}$ coupling impact. Damage in the M1 cab carbody began at the $6 \mathrm{mph}$ coupling impact at the location where the front truck attaches to the side sill on the left side. The damage in the car became worse with each additional impact, culminating in crippling of the side sill in the $12 \mathrm{mph}$ coupling impact. Therefore, coupling speeds should be kept under $6 \mathrm{mph}$ to prevent damage.

A one-dimensional, lumped-mass collision dynamics model for predicting the longitudinal forces acting on the equipment and couplers was developed prior to the test, along with predictions for the conventional coupling tests. It was predicted that damage would occur for coupling speeds between 6 and 8 mph. This compares favorably with the test result that coupling speeds should be kept under $6 \mathrm{mph}$ to prevent damage.

\section{NEXT STEPS}

Additional full-scale dynamic tests are planned which will accomplish the objectives of demonstrating that the locomotive CEM system performs well in service, provides crashworthiness compatibility with a range of equipment, and exhibits increased crashworthiness over conventional equipment. The planned tests are based on a head-on collision scenario in which a locomotiveled train collides with a stationary train. The stationary train can be led by a conventional locomotive, a CEM locomotive, a cab car, or a freight car. The overall objective of these tests is to demonstrate the effectiveness of the locomotive CEM system, comprised of a PBC and a DAC. The first set of tests, the results of which were detailed in this paper, were coupling tests of a conventional F40 coupling with an M1. The second set of tests will be coupling tests of an F40 retrofit with a PBC coupling with an M1 cab car. This arrangement of the tests allows comparison of the conventional coupler performance with the performance of the PBC. The third set of tests will be vehicle-to-vehicle impact tests of a CEM F40 (retrofit with a PBC and a DAC) impacting a stationary vehicle. The final set of tests are planned to be train-to-train impact tests of a CEM F40-led train impacting a conventional stationary train.

Table 3 summarizes the critical measurements for each of the four types of tests. The first two sets of tests, the coupling tests, will demonstrate that the PBC performs as expected in service. The vehicle-to-vehicle tests will demonstrate that the components work together as an integrated system to provide crashworthiness with a range of equipment, and the train-to-train tests will demonstrate the effectiveness of the crashworthy components.

This material is declared a work of the U.S. Government and is not subject to copyright protection in the United States. Approved for public release; distribution is unlimited. 
Table 3. Test descriptions and critical measurements

\begin{tabular}{|c|c|}
\hline Test Description & Critical Measurements \\
\hline $\begin{array}{l}\text { Conventional } \\
\text { Coupling Tests }\end{array}$ & $\begin{array}{l}\text { - Maximum non-destructive coupling } \\
\text { - Dpeed } \\
\text { - Dynamic impact forces } \\
\text { - Impact accelerations } \\
\text { - Displacements }\end{array}$ \\
\hline $\begin{array}{l}\text { PBC Coupling } \\
\text { Tests }\end{array}$ & $\begin{array}{l}\text { - Maximum non-destructive coupling } \\
\text { speed } \\
\text { - Dynamic crush forces } \\
\text { - Impact accelerations } \\
\text { - Displacements } \\
\text { - Effectiveness of PBC }\end{array}$ \\
\hline $\begin{array}{l}\text { Vehicle-To-Vehicle } \\
\text { Tests }\end{array}$ & $\begin{array}{l}\text { - Dynamic crush forces } \\
\text { - Accelerations } \\
\text { - Displacements } \\
\text { - Effectiveness of PBC and DAC } \\
\text { working as a system }\end{array}$ \\
\hline $\begin{array}{l}\text { Train-To-Train } \\
\text { Tests }\end{array}$ & $\begin{array}{l}\text { - Effectiveness of crashworthy } \\
\text { components at managing load path } \\
\text { - Effectiveness of crashworthy } \\
\text { components in inhibiting override } \\
\text { and lateral buckling }\end{array}$ \\
\hline
\end{tabular}

While the overall objective of these tests is to demonstrate the effectiveness of locomotive crashworthiness equipment, the test data will also be used for comparison with analyses and modeling results. The measurements will be used to refine the analysis approaches and models and assure that the factors that influence the response of the equipment are taken into account. Table 3 lists the measurements that are critical in assuring the appropriate modeling and analysis of the equipment.

As of the writing of this paper, efforts are underway to prepare for the second series of tests, the CEM coupling tests. An F40 very similar to the one used in the conventional coupling tests is being prepared for retrofit of the crashworthy components. The $\mathrm{PBC}$ and $\mathrm{DAC}$ are being fabricated for retrofit. An M1 cab car is also being prepared for the tests. The CEM coupling tests are planned for late 2016.

\section{ACKNOWLEDGEMENTS}

This work was performed as part of the Equipment Safety Research Program sponsored by the Office of Research, Development, and Technology of the FRA. The authors appreciate the support and guidance provided by Jeff Gordon, Program Manager, Office of Railroad Policy and Development. FRA staff at TTC helps to coordinate efforts between FRA, Volpe and TTCI. The authors would also like to acknowledge Volpe Center colleague A. Benjamin Perlman for his ongoing technical advice and support in the research discussed in this paper.

\section{REFERENCES}

[1] Mayville, R.A.,Stringfellow, R.G., Rancatore, R.J., Hosmer, T.P., "Locomotive Crashworthiness Research: Executive Summary," DOT/FRA/ORD-95/08, 1995.

[2] Tyrell, D., Severson, K., Marquis, B., Martinez, E., Mayville, R., Rancatore, R., Stringfellow, R., Hammond, R., Perlman, A.B., "Locomotive Crashworthiness Design Modifications Study," Proceedings of the 1999 IEEE/ASME Joint Railroad Conference, Institute of Electrical and Electronics Engineers, Catalog Number 99CH36340, 1999.

[3] Mayville, R., Stringfellow, R., Johnson, K., Landrum, S., "Crashworthiness Design Modifications for Locomotive and Cab Car Anticlimbing Systems," US Department of Transportation, DOT/FRA/ORD-03/05, February 2003.

[4] Tyrell, D., Jacobsen, K., Martinez, E., "A Train-to-Train Impact Test of Crash Energy Management Passenger Rail Equipment: Structural Results," American Society of Mechanical Engineers, Paper No. IMECE2006-13597, November 2006.

[5] Llana, P., Stringfellow, R., "Preliminary Development of Locomotive Crashworthy Components," American Society of Mechanical Engineers, Paper No. JRC201156104, March 2011.

[6] Llana, P., Stringfellow, R., "Preliminary Finite Element Analysis of Locomotive Crashworthy Components," American Society of Mechanical Engineers, Paper No. RTDF2011-67006, September 2011.

[7] Llana, P., Stringfellow, R., Mayville, R., "Finite Element Analysis and Full-Scale Testing of Locomotive Crashworthy Components," American Society of Mechanical Engineers, Paper No. JRC2013-2546, April 2013.

[8] Llana, P., "Locomotive Crash Energy Management Test Plans," American Society of Mechanical Engineers, Paper No. JRC2015-5667, March 2015.

[9] Llana, P., Tyrell, D., Rakoczy, P., "Conventional Locomotive Coupling Tests: Test Requirements and PreTest Analysis," American Society of Mechanical Engineers, Paper No. JRC2016-5817, April 2016.

[10] Carolan, M., Perlman, B., Tyrell, D., Gordon, J., “Crippling Test of a Budd M-1 Passenger Railcar: Test and Analysis Results," Proceedings of the 2014 Joint Rail Conference, JRC2014-3824, April 2014.

[11] Association of American Railroads, "General Code of Operating Rules," April 2015.

This material is declared a work of the U.S. Government and is not subject to copyright protection in the United States. Approved for public release; distribution is unlimited. 